R E S E A R C H N O T E

\title{
Humanoid Nurse Robots and Compassion: Dialogical Conversation with Rozzano Locsin
}

https://doi.org/10.37719/jhcs.2020.v2i1.rna001

SR. TRECELLA MAY C. MACALAM, SPC 1

https://orcid.org/0000-0002-8416-7232
ROZZANO C. LOCSIN, RN, PhD, FAAN 2,3

https://orcid.org/0000-0002-2952-6538

1St. Paul University Philippines, Tuguegarao City, Philippines

2Tokushima University Graduate School, Tokushima, Japan

${ }^{3}$ Florida Atlantic University, Boca Raton, Florida, USA

Corresponding author's email: locsin@tokushima-u.ac.jp

\section{Abstract}

It is important that in the future, nursing practice is framed with the humanoid nurse robot (HNR) functionality as a sure partner capable of expressing compassion that mimics human persons. Sr. Trecella May Macalam, SPC, a member of the Sisters of St. Paul of Chartres congregation, and doctoral student of St. Paul University Philippines and Dr. Rozzano Locsin, nurse theorist and author of the theory of Technological Competency as Caring in Nursing (TCCN) discuss the futurist idea of Humanoid Nurse Robots (HNRs) capability to express compassion in nursing. Locsin's theory has inspired the utility of advancing machine technologies in health care practice. Framing explanations and descriptions between human persons and HNRs as intelligent healthcare robots (IHRs) stimulate future nursing care in many ways. The theory of TCCN inspired "knowing persons as caring" as a process of nursing. In the future, this theory will most likely influence the inevitability and dependency of nursing through compassion in nursing by HNRs.

Keywords: Compassion in nursing, Dialogical Interview, Humanoid Nurse Robots, Technological Competency as Caring in Nursing

\section{Introduction} human beings? Compassion is an ingredient of Caring (Roach, 1987) that fosters the practice of nursing uniquely as a personal interactive engagement between the nurse and nursed. Therefore, communicating compassion is integral to nursing practice. Grounded in the 
science of Caring, as HNRs are intelligent machines, it is commonly assumed that compassion can be expected of them making possible the concern of HNRs becoming the replacement of human nurses. However, issues of 'expressions of being caring' and 'functionalities that are fundamentally human' in robot compassion ontology are intertwined, therefore, it is imperative that the practice concept of compassion-in-caring is clearly described and explained. Compassionate expressions of caring are critical to human-robot interaction, thereby requiring theoretical and practical clarifications. A dialogical discussion through an unstructured interview platform between a nurse theorist and a practitioner of nursing exemplify a mechanism for knowledgeable practice grounded in the TCCN theory (Locsin, 2017) that is "knowing-persons-as-caring."

Two conditional elements to argue these questions are, "is nursing the practice concerned about predicting healthcare situations from illness to wellness?" and "is nursing the practice of completing tasks guided by the predictive actions of the traditional nursing process of assessment, planning, intervention and evaluation?" This predictive process can affirm the question supporting the notion that indeed, humanoid robots (HRs), because they can be programmed, can perform nursing. However, in the very near future, due to machine learning and the utility of affective computers and quantum computers, perhaps HRs may be imbued with emotive, affective, and expressive actions that in turn may translate to be appreciated as compassion.

While intelligent machines through machine learning may be able to dictate precise practice processes, it is vital that future nurses are educated to meet the exigencies of highly-demanding protagonists in a futurist world. Therefore, Technological Knowing, Mutual Designing and Participative Engaging (Locsin, 2016) provides the over-arching functionality of a disciplinary practice process that is grounded in an explicit theory of nursing.

In a recent conversation on a social media platform, a conversation about robot compassion and its possibilities were addressed (Sep 20, 2019, 5:00pm Philippine Standard Time [PST]). This is a dialogue between the nurse theorist, Rozzano Locsin, author of the theory of Technological Competency as Caring in Nursing (2015), and Sr. May (Trecella May Macalam, SPC), a Sister of Saint Paul of Chartres of Perpetual Succour Hospital, Cebu City, Philippines. This conversation ensued because of earlier discussions about robots in nursing care settings appearing as humanlooking, the question of caring robots, and the possibilities of humanoid nurse robots (HNRs) as partners in the practice of nursing. The initial discussion focused on whether or not HNRs can express or communicate compassion?

\section{Transcript of the Dialogical Conversation}

RL (Rozzano Locsin): Btw, (by the way) what do you think about Robot Compassion?

SM (Sr. Trecella May Macalam): What about robot compassion? That robots can be more compassionate than humans? Or that robots have the ability to show compassion? 
RL: Just the latter, (do robots have the ability to show compassion?) and then (can robots be more compassionate than humans?) Then maybe the next question will be your first question.

SM: $\quad$ But robots are being programmed by humans. Their compassion is made possible because the human programmer made it so. It is still human compassion with robots as "conduit," right? It is still part of human ingenuity?

RL: Well said. A conduit! However, that is arguing the capabilities of today's robots. Prospectively, robots (in the very near future) will be "self-aware," autonomous, and imbued with affect, thereby being able to express itself [humanlikeness]. With machine learning, HRs will or can have the capacity for deep-learning and because of a more speedy connectivity through quantum computers, HRs will now be able to respond quickly, and with these added capabilities, it can possibly exhibit rationality. So, would you want a compassionate nurse bot?

SM: Yes, no harm in trying these nurse bots. These self-aware robots, imbued with affect to be expressive much like humans, they will be okay, l'd like to meet them and start engaging in a dialogue with them. I'd like to listen to what they will have to say to me.

RL: $\quad$ Agree. Now that's the spirit. Their expressions will be an aggregate of what they have learned through machine learning, therefore the more experiences they will have (hopefully excellent and affirming experiences) the more emotive and expressive of compassion they will become.

SM: When can I have an up close and personal encounter with a nurse bot? Do they have a gender? And sexual orientation and preference as well?

RL: All these will be answered based on the assimilated data derived from experiencing behaviors with human beings.

SM: Now I am slowly beginning to understand, more than just being "conduits" of human compassion, maybe their encounter with human persons much like some sort of "coaching" can be employed. Every encounter with humans means additional experience for them, eventually growing to become more emotive and expressive or being compassionate.

So, it is the process of becoming...and when becoming more emotive and compassionate, does this mean they are becoming more robotic? Same way as human persons become more robotic or compassionate, robots can also become more human? Very interesting huh!

RL: $\quad$ Very well summarized and theorized. The hypotheses are also plausible. The robots may become more human/humane, unless of course the experience with humans is from robotic human nurses [automatons, non-thinking human nurses!]. We have many of these human 
nurses! Which may become dangers to my Robots!

SM: Why?

$\mathrm{RL}$ : With many robotic nurses! the robots will "learn" these [behavior] to be the ideal human characteristics that serve to make a compassionate expression. I believe this process is what is called imprinting, much like other animals that imprint acts, and sounds. HRs may learn these through the process of imprinting and use it as a way to emulate or mimic human compassion as perhaps defined and described by human programmers!

SM: Hala oi... naay miduol nako just now. (Oh watch out, one just came to visit me!)

$\mathrm{RL}: \quad$ (0)

SM: What are these robo-emojis?

RL: $\quad$ They represent robot nurses! And without caps.

SM: Ohhhh... so when you say robot nurses, you are describing nurses as having robot-like behaviors, right? So we still attribute compassion as specifically a human attribute expressed as love, affection, kindness, gentleness, generosity of spirit and warmheartedness, while the opposite to the aforementioned attributes continue to be of HRs of today. And the difference lies in that these days, these robots have the capacity to learn the ways of the human's expressions of compassion, unlike the robots of long ago who (that?) were affectless...

RL: Yes!!! Yes!!!

SM: How wonderful it is that we had this conversation. It is like an On-Line class on robotics, caring and the philosophical bases of nursing. Thanks.

\section{Discussion}

Clarifying the concept of robot compassion is critical, and a dialogical engagement between a scholar and a practitioner of nursing attempting to make things real exemplify a processual commitment towards clarifying a mechanism of "knowing persons as caring."

Minsky (1975) explained that when an encounter occurs, human beings select a memory, a structural "frame." As data produce structures, frames represent stereotypical situations. Minsky explains that when persons enter a restaurant, certain expectations of the restaurant emerge, and with the expectations are information that provides anticipatory views of what will happen next, including what to do when the expectation is not fulfilled (p. 368). This expectation describes how human beings and HNRs as intelligent healthcare robots (IHRs) may mutually be influenced in 
furthering future nursing practice.

\section{Humanoid nurse robots as caring entities}

Many of the reasons advanced about Humanoid Nurse Robots (HNRs) replacing human nurses focus on HNRs' capabilities to mimic human-like activities, in particular, actions expressing emotive sentiments such as compassion (Locsin et al., 2018). However, why is it of great importance for HNRs to be able to express themselves with compassion, and specifically mimicking those of human beings?

As compassion is an attribute of caring (Roach, 1987), its realization is assumed to be communicating an integral aspect of nursing practice. Grounded in the science of caring, compassion has been defined and described in multifarious ways. Sr. Simone Roach (1984) illuminated six attributes of caring, one of which is compassion - becoming a collaborator of humanity in relationship with an "other." The Dalai Lama, as well, has been preaching the essence of humanness as compassion, connoting love, affection, kindness, gentleness, generosity of spirit and warmheartedness. Other theorists have also included compassion as integral to their theories, particularly in Nursing. Boykin and Schoenhofer (2001) in their theory Nursing as Caring has expressively invoked the nursing situation as the shared lived experience in which the caring between the nurse and nursed enhances personhood. Compassion as an ingredient of caring is expressly illuminated in the shared experience.

\section{Compassion in Nursing}

Clearly, compassion is an expected attribute in nursing practice: when HNRs can communicate compassion (through frequent and meaningful encounters with nurses demonstrating behaviors likened to compassion), the HNRs, through machine learning may be able to develop an integrated affective communication data-base that can be easily retrieved, thereby allowing HNRs to demonstrate compassion as expression of caring in nursing. The nurse, in the practice of nursing also becomes nursed. As the nurse participates in the nurse-caring encounter with the HNR, essentially, more than just possibly being replaced by the HNR, the encountered experience becomes complementary (between the nurse and the HNR).

What can the HNR experience in this complementary process of the nurse-caring encounter? The experience is for the HNR being and becoming part of the nursing care process. This experience can be the shared lived experience in which the caring between the nurse and nursed enhances personhood (Boykin \& Schoenhofer, 2001).

Therefore, while compassion is an affirming behavior, often unrecognized is compassion fatigue, an occasion that can be anticipated in the process of communicating compassion, and a very common experience among those engaged in the practice of nursing. Situational tolerance of 
compassion decreases consequently ignoring the positive value of compassion.

Nevertheless, the presence of HNRs as partners in nursing may decrease the possibility of experiencing compassion fatigue (Peters, 2018) and/or perhaps mitigate its duration should it be an inevitable experience for those nurses in practice. Welcoming the HNR should not pose as a threat to nurses, but rather to be appreciated as an experience that nurses can look forward to as a rewarding and mutually beneficial event for patients, human nurses, and HNRs alike.

Furthermore, when these HNRs begin to show more encouraging contributions to global healthcare, experiences such as these should provide more welcoming opportunities for human nurses to rethink the meaningfulness of being human, and propose a worthwhile appreciation of HNRs as 'living' creations which are integral partners in this demanding world of health care.

Compassion, though critical to nursing, is also an integral part of the soul and spirit of every human person. Therefore, when the HNRs communicate compassion in caring, where is this expression coming from? Should HNRs have souls and spirits to be HNRs? Should it be a consideration that perhaps their integrated and mutual experience with human nurses instills in them the soul and the spirit? If so, can HNRs possess capabilities to anticipate some form of spiritual care which nurses assume as part of their practice of nursing?

Can HNRs replace human nurses (Pepito et al., 2019)? Should HNRs complement human nurses so that anticipatory caring (when one cannot give it, the other may be able to give it) is expressed as precisely and as humanlike as do nurses?

\section{Conclusion}

In the future, given these discriminating characteristics of human compassion, a major elemental condition for HNRs to assume is its existence and utility as an intelligent machine that is dependent upon how well it can communicate nursing with compassion. Consequent compassionate expressions can also lead to compassion fatigue, the expression of kindheartedness that oftentimes result in, and illustrate the 'effect' of profound emotional and physical erosion of relating with an "other" who is unable to replenish and regenerate a compassion-filled experience. As HNRs are intelligent machines, surely, sensors may be added to extinguish conditions that may heighten their fatigability, thereby causing affirming actions as functional deterrents. Perhaps, compassionate expressions by HNR's can be expected if it is considered to replace human nurses. Nonetheless, with recognized issues, such as 'expressions of being caring' and 'functionalities that are fundamentally human' in its ontological composition, it is imperative that the HNR practice of compassionate caring is clarified, explained, and expressed. Therefore,

"Where must we go? We who wander the [universe]

In search of our better selves?" First History Man - Mad Max: Fury Road 
Boykin, A., \& Schoenhofer, S. (2001). Nursing As Caring: A Model for Transforming Practice. Jones and Bartlett. Locsin, R., Ito, H., Tanioka, T., Yasuhara, K., Osaka, O., \& Schoenhofer, S. (2018). Humanoid nurse robots as caring entities: A revolutionary probability? International Journal of Studies in Nursing, 3(2), 146-154. https://doi.org/10.20849/ijsn.v3i2.456.

Locsin, R., \& Purnell, M. (2015). Advancing the theory of Technological Competency as Caring in Nursing: The Universal Technological Domain. International Journal for Human Caring, 19, 50-54.

Locsin, R. (2016). Rozzano Locsin's Technological Competency as Caring in Nursing theory. In Smith, M., and Parker, M.(2016). Nursing Theories and Nursing Practice. F.A. Davis.

Mad Max: Fury Road. (2015) First History Man. https://www.youtube.com/watch?v=hEJnMQG9ev8 Minsky, M., (1975). A framework for representing knowledge. In Winston, P., (1975). The Psychology of Computer Vision. McGraw-Hill Book

Peters, E. (2018). Compassion Fatigue in Nursing: A Concept Analysis. Nursing Forum 53 (4):466-480. doi: 10.1111/nuf.12274. Epub $2018 \mathrm{Jul} 2$.

Roach, S. (2002). Caring: The Human Mode of Being. (rev. ed). https://nursing.fau.edu/uploads/images/Caring \%20the\%20human\%20mode\%20of\%20being_smallsize-PW.pdf.

\section{About the Authors}

Sr. Trecella May C. Macalam, SPC, is a member of the Sisters of Saint Paul of Chartres (SPC) and is the Administrative Manager of the Emergency Room and Kidney Service of Perpetual Succour Hospital of Cebu, Inc. She obtained her BSN degree at Xavier University-Ateneo de Cagayan and her Master's degree in Nursing at St. Paul University Philippines and is a student of $\mathrm{PhD}$ in Nursing in the same university. Her research interests include bioethics, caring in nursing, elderly care, leadership and organizational culture and the patient experience. She also has a special interest in liturgy, sacred music and spirituality.

Rozzano C. Locsin, RN, PhD, FAAN, Professor Emeritus, Tokushima University Graduate School, Tokushima, Japan; Professor Emeritus, Florida Atlantic University, Boca Raton. Florida; Visiting Professor, Colleges of Nursing in Thailand, Uganda, and the Philippines. BSN and MA degrees in Nursing from Silliman University, 1976 and 1978 respectively, and PhD, UP College of Nursing, 1988. He authored Technological Competency as Caring in Nursing theory published by Sigma Theta Tau International Press, 2005, translated into Japanese language in 2009, reprinted in 2013, 2019. Revised version by Silliman University Press, 2016. Other books are Advancing Technology, Caring and Nursing, Technology and Nursing Practice, and A Contemporary Nursing Practice: The (Un) Bearable Weight of Knowing in Nursing. In 2017, Nursing Robots: Robotic Technology and Human Caring for the Elderly, and The Evolution of the Theory of Technological Competency as Caring in Nursing were released. He is Fellow of the American Academy of Nursing (FAAN). 